\title{
BIOLOGICAL HAZARDS AND TOXICITY OF RADIOACTIVE ISOTOPES
}

\author{
BY AUSTIN M. BRUES
}

(From the Biology Division, Argonne National Laboratory, Chicago, Illinois)

Clinical use of radioisotopes requires careful consideration of their human toxicity, both from the standpoint of the patient and from that of the individuals who must handle the isotopes before administration and the excreta afterwards. One must take into account not only the possibility of acute overdosage but also the potentially serious end-results of the fixation in the body of isotopes, particularly those of long half-life, which may lead to chronic radioelement poisoning.

Such information as we have regarding radioisotope toxicity is largely indirect. Knowledge of the physical characteristics of the radiation emitted by an isotope, combined with information regarding its metabolic fate, enables us to make approximate calculations of tissue dosage. The pathologic effects of a given tissue dosage have been ascertained only in a few instances, using experimental animals ; in other instances pathologic consequences of isotope administration are described but the exact tissue dosage has not been established. Translation of these results to man has been attainable only in the case of radium, where it is known that malignant tumors have occurred in individuals harboring less than one-hundredth the tissue concentration necessary to produce comparable results in experimental animals. Yet the catastrophic consequences of radium absorption in a relatively small number of exposed human subjects have resulted in a wholly justifiable conservatism in our attitude towards human exposure to other radioelements.

\section{Units and Dosage Calculations}

In the case of external $X$ or gamma radiation, the roentgen $(r)$ is a well-established unit having an exact physical meaning based on the measurement of ion concentration in air. It has the dimensions of energy per unit of mass, and is approximately 83 ergs per gram of air. From this has been derived the rep (roentgen equivalent physical) or e.r. (equivalent roentgen), describing the amount of alpha or beta radiation causing equivalent energy release. Energy release in soft tissue is approximately (but not exactly) the same as in air on a mass basis.
In the case of alpha radiation, it is known that the biological effectiveness differs from that predictable from the roentgen equivalence. This is due to the increased local density of ionization along the alpha ray track. The consequences of this vary (1) but in the case of toxicity to the higher animals the alpha rays are five to ten times as effective as beta rays yielding equivalent energy. ${ }^{1}$ Parker (2) has introduced the unit "rem" to signify equivalence to the roentgen unit in terms of mammalian toxicity.

Computation of tissue dosage is most readily made in the case of a mass of tissue infinitely large with respect to the radiation, and with the isotope distributed homogeneously therein. The dosage is then given by the familiar formula.

$$
\mathrm{rep} / \mathrm{day}=60 \times \mathrm{E}_{\mathrm{m}} \times \mathrm{C}
$$

where $\mathrm{C}=$ concentration of isotope in $\mu \mathrm{c} / \mathrm{g}$ or $\mathrm{mc} / \mathrm{kg}$, and $E_{m}$ is the mean energy of the radiation in million electron volts. The mean energy of beta rays from the common isotopes is not always precisely known, but onethird of the maximum energy serves as a fair approximation.

Where the surface of such a mass of tissue approximates a plane, the dosage at the surface will obviously be one-half of that calculated above; this situation applies to the beta radiation at the surface of a thyroid containing radioiodine. Beta dosage from other sources which may be defined in simple geometry can be calculated only in so far as the beta ray spectrum is clearly defined; the author has attempted to do this in relation to mitotic changes around a point source in tissue (4). Further discussion of tissue dosage will be found in the paper in this issue by Marinelli (5).

\section{Nature of Isotope Toxicity}

The toxicity of an isotope given in high dosage may manifest itself as an acute reaction resembling acute radiation sickness. This will occur in its purest form where the tissue radiation is homogeneous throughout the body and approaches the lethal dosage (which, for man, is in the vicinity of $500 \mathrm{r}$ in the case of a single exposure to X-rays). This syndrome $(6,7)$ is a complicated one depending in part on the destruction of the more radiosensitive cells (particularly of the blood-forming

\footnotetext{
1 It is possible that the weak beta emitter, tritium $\left(\mathrm{H}^{3}\right)$ will fall in the same category as the alpha ray emitters, due to density of ionization in the very short path of the beta ray.
} 
organs) and on the release of heparinoid substances into the blood (8). Administration of the short-lived $\mathrm{Na}^{24}$, which equilibrates with the body sodium, may be expected to elicit the syndrome of total-body radiation. It is of interest that the consequences of injecting a pure bone-seeking isotope (as $\mathrm{Sr}^{89}$ ) in high dosage are quite similar (6), suggesting that bone marrow radiation may be a large component in the acute radiation syndrome. The relative resistance of the mouse to acute radiation anemia following $\mathrm{Sr}^{89}$ administration may be attributable to the tendency of this species to develop ectopic myelopoiesis in the spleen (9). $\mathrm{P}^{32}$, because of its tissue distribution, may be expected to approximate the pattern of the acute radiation syndrome.

Subacute radiation reactions occur where external $\mathrm{X}$ or gamma radiation is given intermittently or continuously over a long period, or where an isotope of sufficient half-life is retained in high dosage. In its pure form, aplastic anemia is the predominant feature (6). Other effects may occur where the tissue distribution creates a special case. The most carefully studied instance is that of the radioelements which occur in high concentration in the liver. Here, after several weeks, necrosis, cell damage, hyperplasia and fibrosis occur and lead to hepatic insufficiency. Where mice or rats have been injected with radiocerium, the thin edge of the liver, in which radiation dosage is relatively small, may undergo hypertrophy while the bulk of the liver shows necrotic changes.

It is the nature of late or chronic radiation changes which sets the limits of permissible exposure. The chronic insult of a long-lived retained radioelement may result in the gradual development of morbid changes punctuated, after a long latent period, by carcinogenesis. Thus, human radium poisoning may result in bone sarcoma where the retained dose is in the order of one microgram, and sarcoma of the liver has occurred several years after administration of colloidal thorium dioxide (10). Experimental investigation, which has been done on short-lived animals, has yielded comparable results but only with much higher tissue dosage due largely, no doubt, to the shorter period of observation.

It must be remembered that dosage does not have to be given over a long period of time in order to result in malignant changes. This is shown, in the case of man, by the series of bone sarcomas following X-ray dosage of $1500 \mathrm{r}$ and above (11). It appears clearly that external beta radiation of rats is effective in producing skin and subcutaneous malignant tumors in single, as well as daily, dosage (12). Single dosages of 3,000 rep were effective after a considerable latent period (eight to 12 months). Analogous results have been seen following the feeding, either in single or daily dosages, of radioyttrium (13). While tissue dosage calculations are virtually impossible, it is clear that both single and repeated treatments yield carcinomas of the colon. It seems fair to state that in no instance do we have clear information relating the dosage required for carcinogenesis as a function of time-distribution of treatment; in other words, the recovery factor is unknown (14).

\section{"Tolerance" or Permissible Dose}

No doubt the most difficult datum to obtain experimentally is the one most in demand by users of radioisotopes, namely, the amount of radiation exposure which may safely be withstood. We do not, in fact, know whether a threshold exists for such measurable evidences of morbidity as shortening of life or cancer, while in the case of genetic changes it seems likely that no threshold dosage exists below which there is no probability of radiation-induced mutation. In the matter of human permissible exposure, we rely upon two basic "tolerance" values: the permissible retained amount of radium has been set at $0.1 \mu \mathrm{c}$, since this is one-tenth of the amount known to have morbid consequences, and the permissible daily $\mathrm{X}$-ray dosage has been taken as $0.1 \mathrm{r}$ daily, for similar reasons. The National Committee on Radiation Protection has recently recommended reducing the latter figure to $0.3 \mathrm{r}$ per week. This action takes into account recent experimental evidence which shows that detectable consequences may follow daily administration of dosages below $1 \mathrm{r}$ daily, and also implies that a dosage of $0.3 \mathrm{r}$ will probably differ little in its freedom from consequences whether administered at once or over an extended period. Indeed, the clinical results of a single dosage of $15 \mathrm{r}$, measured as the lymphocyte response, are on the threshold of clinical detectability.

Permissible levels for radioisotope exposure must, in general, be derived from the two figures 
cited above, in combination with experimental work which may relate toxicities of bone-seeking isotopes to radium (as in the data on $\mathrm{Sr}^{89}$ to be discussed later) and with calculations of tissue dosage based on what metabolic information is available. Such calculations are described by Morgan (15) and by Marinelli et al. (16). Levels so derived must, of course, be accepted with certain reservations : where they depend upon average figures for absorption, the great variation existing even between "normal" human beings must be taken into consideration, and where they depend upon mean concentration in a critical organ, we must be certain whether the radiation is actually homogeneous throughout the organ. Moreover, we must always be prepared for unexpected experimental results. Thus, plutonium ${ }^{239}$ was found to be about 50 times as effective as radium, on the basis of physical comparison, in producing acute radiation disease (17), no doubt due to its very heterogeneous tissue distribution, while $\mathrm{Sr}^{89}$ has likewise been relatively more potent than expected in bone tumor production.

\section{Justification for Dosage Exceeding the Permissible}

As noted above, the permissible dosage of external radiation is expressed as a daily or weekly amount, applied to the whole body. It can probably safely be assumed that most topographic or histologic parts of the body can receive larger dosages, as in the case of exposure of the hands. Consideration of the methods used in deriving permissible dosages will show the rather general impossibility of deriving data applicable to various parts of the body.

It also seems that a single dose in excess of the daily permissible level can be defended under some circumstances; for example, much routine radiography results in dosages exceeding daily or weekly "tolerance."

With firmly deposited isotopes of long halflife, the daily dose is necessarily continued after deposition. The tendency in this case has been to calculate the amount, giving the maximum permissible level to the critical organ at the height of its concentration there.

The foregoing discussion applies to permissible levels of radiation exposure for normal individuals who receive their exposure industrially or profes- sionally. Various ranges of exposure may be justifiable, depending upon the nature of the population or upon the reason for administration. They are indicated below, in ascending order of exposure level.

a. The large population: Because of the statistical nature of the genetic sequelae of the lowest dosage levels, it is probably correct to consider that a large population should not be permitted to become exposed to a level of radiation comparable with that which can be justified in special cases. It is likewise possible that tumor development may be slightly enhanced by dosages under "tolerance," but no evidence on this point is available. In the matter of recessive mutations, the size of the exposed population will, of course, determine the probability that, with random mating, the same recessive will occur in both gametes in a later generation. It is, however, probably unnecessary to prescribe levels less than one-hundredth of "permissible," since this level approaches that of the cosmic radiation and the radioactivity normally present in the body.

b. The small, professionally exposed population: It is for such populations that the permissible levels have been applied. Although a possibility of minimal effect, perhaps not detectable, is not ruled out by our present knowledge of the radiobiologic effects of small dosages, it will be recalled that various other industrial and other hazards exist which, again, are merely reduced to the imperceptible level. No low-level hazard has been as carefully studied as that of external ionizing radiation.

c. Clinical investigation and diagnostic procedures: Where such a reason exists for isotope administration, we may fall back on the precedent of diagnostic radiography. Thus, a total dosage of beta and gamma emitters between 1 and 10 rep to the critical tissue may be justified, if not repeated, in the case of certain isotopes of short halflife whose metabolic fate is well understood, e.g., $\mathrm{Na}^{24}, \mathrm{~K}^{42}, \mathrm{I}^{131}$, and possibly $\mathrm{P}^{82}$. For the present, the bone-seeking isotopes in general, as well as those whose metabolic fate is in doubt ( $\mathrm{C}^{14}$ in particular), should not be used in this category. Isotopes in a borderline class include $\mathrm{Fe}^{55}, \mathrm{Fe}^{50}, \mathrm{Ca}^{45}$, and the long-lived isotopes $\mathrm{Na}^{22}$ and $\mathrm{Cl}^{36}$; with these, somewhat more caution is indicated than with the shortest-lived radioelements. As examples of actual practice, $\mathrm{Na}^{22}$ has been used in 
normal subjects (18) in such a way as to yield somewhat less than 1 rep total integrated dosage (90 $\mu \mathrm{c}$ in man) ; $\mathrm{Fe}^{55}$ and $\mathrm{Fe}^{59}$ have been used in normal blood donors (19) in such dosage as to yield a maximum of 0.1 rep per week in blood. $\mathrm{P}^{32}$ has been given to human subjects to establish its turnover in tumors, including operable tumors. In one recent study, $1 \mu \mathrm{c}$ per pound body weight was used and it was estimated that the total-body irradiation would not exceed 1.5 r (20) (integrated over time and over the body volume). The attitude toward $I^{131}$, on the other hand, has been somewhat more liberal, presumably because this isotope is virtually confined to the thyroid. Thus, for diagnostic purposes, 20 rep per day to a total dose of 230 rep has been given as calculated thyroid dosage (21).

It is clear that improvements in technique of measurement of isotopic radiation will greatly benefit work in this area, since many studies will be brought within the limits of reasonably safe operation. As it is now possible actually to estimate naturally occurring $\mathrm{C}^{14}$ within $5-10$ per cent (22), this is an important direction in which clinical isotope work can find new opportunities.

$d$. Treatment of disease where other therapy is available: In this range, dosage must necessarily far exceed that required to produce visible changes in the organism, since changes are being sought. The principle of calculated risk is therefore paramount, as indeed it is in all clinical therapy and especially in surgery. There are, however, certain pervading differences. In the first place, the risks in surgical and pharmacologic therapy are mainly immediate, easily observed and soon calculable; whereas in isotope therapy the most important risks may be disclosed by the passage of a considerable amount of time, as shown by the results of radium absorption and by the late consequences of the use of colloidal thorium dioxide (even where used for diagnostic purposes) (10): Secondly, there are certain unknown factors which make calculation of risk, to an order of magnitude, impossible. We do not know the relation between latent period before carcinogenesis and the lifespan of a species, or the relations between the probability of tumor development and the volume or type of tissue irradiated or the time distribution of radiation. On a more basic level, we understand next to nothing about the mechanism of radiation carcinogenesis or the meaning of the shortening of life after total-body irradiation.

In two instances, there is a fairly large backlog of experience in therapy of disease with radioisotopes. These are the treatment of benign thyroid disease (especially exophthalmic goiter) with radioiodine and of leukemia and polycythemia vera with $\mathrm{P}^{32}$. Therapy of polycythemia vera has yielded results similar to those of $\mathrm{X}$-ray given to the whole body, and is logical inasmuch as bone marrow receives a larger dosage than the integrated total-body dose. One mc administered to a $60 \mathrm{~kg}$ man yields an integrated total body dosage af about 15 rep, neglecting loss by excretion, at a rate less than 1 rep per day; the bone marrow, spleen, and lymph nodes may receive two to three times as much. Thus, dosages of 1-5 mc correspond to total-body X-ray treatment ranging between 15 and $75 \mathrm{r}$, or somewhat more to bone marrow. The time distribution of the radiation probably makes it somewhat less toxic (and less effective) than $\mathrm{X}$-ray given according to usual patterns of treatment.

Although dosages of this sort are in accord with regular practice in radiation therapy, it is possible that deleterious results may occur. This has been suggested by Hall and Watkins (23) in whose series of $\mathrm{P}^{32}$-treated cases a number of acute leukemias arose. Because of the frequency of chronic leukemias and leukemoid states arising in the course of the disease, it is difficult to evaluate these results until further information is available. Our own observations (24) show that $\mathrm{P}^{32}$ is leukemogenic to mice, but that the effect is not strikingly different from that of total-body X-ray in equivalent dosage.

In treatment of thyrotoxicosis, $\mathrm{I}^{131}$ has been used in relatively high thyroid dosage by a number of clinical groups. This question has been discussed recently by Nickson (25). Dosage of 200 or more microcuries per gram of thyroid are frequently used, with a resultant total radiation dose in excess of 10,000 rep. The actual dose has been estimated to be as much as 26,000 rep with $200 \mu \mathrm{c} / \mathrm{g}$ (26), but is difficult to estimate, since it depends on the rate of loss of iodine from the treated gland. If the dose to the tissues immediately surrounding the thyroid is one-half to onefourth of this, it appears that the adjacent connective tissue receives thousands of rep. This is 
in the range of dosage by $\mathrm{X}$-ray which has resulted in bone tumors in man (11), and it will be recalled that 3,000 rep of external beta radiation to rats from $\mathrm{P}^{32}$ has resulted not only in epitheliomas, but in subcutaneous sarcomas as well (12). It is, therefore, within the bounds of possibility that carcinogenic effects may occur from dosages as used in the treatment of thyrotoxicosis, although it is encouraging to note that no reports of such sequelae have appeared after several years' clinical experience.

An intermediate group of diseases exists, namely the leukemias and allied disorders, in which certain isotopes $\left(\mathrm{Na}^{24}\right.$ [27], $\left.\mathrm{P}^{32}, \mathrm{As}^{78}[28]\right)$ are used in place of total-body radiation for similar palliative purposes. In all of these instances the net effect of the radiation is either equivalent to that of total-body X-ray, or it is distributed in favor of bone marrow and blood-forming organs. Since the peripheral blood picture gives indication both of toxicity and of therapeutic effectiveness, it is useful in monitoring treatment. It should be recalled that the same general remark applies to the use of radiomimetic chemicals, e.g., the alkylamines.

e. Treatment of hopeless malignant disease: Here it would seem justifiable to use whatever means offer some chance of palliation or cure, or of gaining information to that end where this can be done without detriment to the patient. In the case of metastasized malignant disease of the thyroid, it would seem proper to treat every patient with $I^{131}$ in order to determine the response. Although certain histologic types have been found not to concentrate iodine (29), it has been shown that the capacity to store this element may be enhanced by thyroidectomy or administration of thyrotrophic hormone. Dosages have been large; in one case (29) where the dose to the normal thyroid is stated, the gland should have received 36,000 rep on the first day (assuming immediate uptake) to an ideal total (barring subsequent loss) of 430,000 rep. Treatment in this order of magnitude has been possible only in the treatment of thyroid disease. Dosage to metastases in this case was $1 / 70$ of that to thyroid (viz., about 6,000 rep).

In breaking new ground, the long-lived isotopes will be tested. The possibilities of $\mathrm{C}^{14}$ and $\mathrm{H}^{3}$ in organic compounds are manifold, and es- sentially no exploration has been done at the present time. The use of $\mathrm{Sr}^{89}$ has also been suggested. Because of the known chronic toxicity of the latter and the potential hazard in the use of other long-lived isotopes, it will be essential that cases be selected on the basis of inoperability. It may be suggested that all patients be chosen (1) as a result of biopsy from a metastatic lesion, or a primary lesion deemed inoperable or (2) after consultation with a specialist in this particular field. There are few physicians who have not, on some occasion, misjudged the prognosis of a clinical situation resembling inoperable cancer. It has also been advocated that such treatment be given only after exhaustive experimental study. This is desirable in cases where the toxicity of the isotope or the isotopic compound is unknown, but it should be recalled that the variety of human cancer is greater than that easily available in laboratory animals, so that the appropriateness of the treatment for a given tumor type may need to be evaluated by tracer studies in patients, or (for $\mathrm{C}^{14}$ ) by use of the stable $\mathrm{C}^{13}$.

As mentioned before, the short-lived isotopes, and especially those yielding hematologic changes as readily as total-body X-ray, may be used with the same precautions as are used with external radiation or chemotherapeutic agents, as far as the patient is concerned. It will be seen that the short-lived isotopes may be intense radiation sources and require special care during preparation and administration.

\section{Toxicity of Bone-seeking Elements}

In order to gain some quantitative expression of the carcinogenic action of radioactive substances which might have general meaning, large series of animal experiments were set up in this laboratory using $\mathrm{Sr}^{89}$ in rats and mice. It was hoped thereby to observe the pattern of bone tumor induction (as pilot experiments had shown [30]) by a very potent carcinogen the effectiveness of which was due to beta irradiation of bone. A preliminary discussion of these experiments was included in our earlier report (14). The data are still incomplete pending histologic verification of the gross pathologic findings. One of the strains of mice used has shown an unexpectedly high incidence of bone lesions of various sorts, including benign tumors. 
Experimental: The mice used in these experiments were females of the Carworth CF-1 strain and male and female ABC hybrid mice obtained from the Roscoe $B$. Jackson Memorial Laboratory. These mice were chosen because of their ready availability in large numbers at the time the experiments were begun $(1945-6)$ and because they had no specialized tumor characteristics which might obscure the study of the general tumor hazard, except for a high incidence of spontaneous lymphoma and lymphatic leukemia. A few highlymphoma C58 strain mice obtained through the kindness of Dr. E. C. MacDowell were also used.

The animals were housed in an air-conditioned animal farm to permit regulation of temperature ( $\operatorname{circa} 23^{\circ} \mathrm{C}$.). Triethylene glycol vapor was used to minimize the possibility of air-borne cross-infection. The mice were received in lots of over 600 , equally divided among the three permutations of strain and sex. One-fifth of the total experiment, including aliquots of the dose levels used, was set up upon receipt of each shipment, and injected at $42 \pm$ seven days of age. Each component group of animals remained caged together throughout the experiment. It was found that certain cages of animals suffered from infectious disease, but cross-infections to nearby cages were rare. The commonest infectious diseases were pneumonia (with intracellular pleuropneumonia-like organisms) and intestinal or generalized infections due to Salmonella and Pseudomonas.

Since the acute lethal dose (30-day $\mathrm{LD}_{s 0}$ ) for $\mathrm{Sr}^{\infty}$ in mice was found to be $8 \mu \mathrm{c} / \mathrm{g}$ body weight, the highest single dosage used was $5 \mu \mathrm{c} / \mathrm{g}$, and lower dosages were employed, differing by factors of approximately 2, down to $0.05 \mu \mathrm{c} / \mathrm{g}$. A parallel series was given monthly dosage with one-fifth of the above amounts in such a way as to bring the dosage to the same level each month. Increasing numbers of mice were used in the lower dose levels in order to maintain statistical significance, if possible, where tumor incidence would be less; the design of the experiment is shown in Table I.

All mice were observed daily; those showing evidence of serious disease were followed with particular care and sacrificed when in extremis. By adequate clinical observation it became possible to salvage over 95 per cent of the fatally ill animals before death. Complete autopsy (except for the central nervous system) was performed,

TABLE I

Design of large mouse experiment with Sr89

\begin{tabular}{|c|c|c|c|}
\hline Dose & $\begin{array}{c}\text { Single } \\
\text { injection }\end{array}$ & $\begin{array}{c}\text { Monthly } \\
\text { injections }\end{array}$ & Dose \\
\hline $\begin{array}{l}\mu c / 8 \\
5 \\
2.5 \\
1 \\
0.5 \\
0.25 \\
0.1 \\
0.05 \\
\text { Control }\end{array}$ & $\begin{array}{c}\text { number of mice } \\
45 \\
60 \\
90 \\
150 \\
240 \\
240 \\
240 \\
480\end{array}$ & $\begin{array}{c}\text { number of mice } \\
45 \\
60 \\
90 \\
150 \\
240 \\
240 \\
240 \\
480\end{array}$ & $\begin{array}{l}\mu c / 8 \\
1 \\
0.5 \\
0.2 \\
0.1 \\
0.05 \\
0.02 \\
0.01 \\
\text { Control }\end{array}$ \\
\hline
\end{tabular}

sections were taken where considered necessary, and the carcasses preserved in 4 per cent formaldehyde. Roentgenograms were made in all cases at or after death.

\section{RESULTS}

Survival was definitely shortened at the higher dosage levels, as might be expected. This is illustrated graphically in Figure 1, in which a separate family of curves is shown for survival of the groups injected singly and monthly. Because of the obvious similarity among the types of mice used with reference to longevity and bone tumor genesis, they have all been pooled in assembling the data in preliminary form. The last survivor in the $\mathrm{ABC}$ female control group died 895 days after the beginning of the experiment (about 937 days of age) and the last CF-1 female died after 876 days (about 918 days of age). The ABC male group in the experiment was shorter-lived, falling (for the last 5 per cent of survivors) about 100 days behind the females of the same strain.

Even at the highest dosages, no "acute" radiation deaths occurred during the first month. The earlier mortality among these mice is not ascribable to any single cause. In addition to bone tumors, aplastic anemia and myeloid metaplasia (the latter probably a compensatory response) (9) were commonly observed at autopsy, and graying of hair, which is a frequent subacute sequela of total-body radiation, was noticeable. Of the mice receiving $5 \mu \mathrm{c} / \mathrm{g}$ and surviving 200 days, 35 per cent died before 250 days without bone tumors and an additional 14 per cent, with bone tumors; of the controls, 5 per cent of the 200-day survivors died in the same period.

Incidences of tumors, other than those arising in or near bone, have failed to undergo changes attributable to the treatment. A small apparent increase in lymphomas in the heavily-treated CF-1 and $A B C$ mice has been shown to lack statistical significance.

Tumors in or near bone were of several types; osteogenic sarcomas predominated, but other malignant tumors of mesenchymal and endothelial origin have been observed, and for statistical purposes have been included with those of osteoid origin. Multiple primary tumors occurred with an entirely random frequency, their incidences conforming well to the Poisson distribution. Thus, multiple tumors are more frequently seen as the 


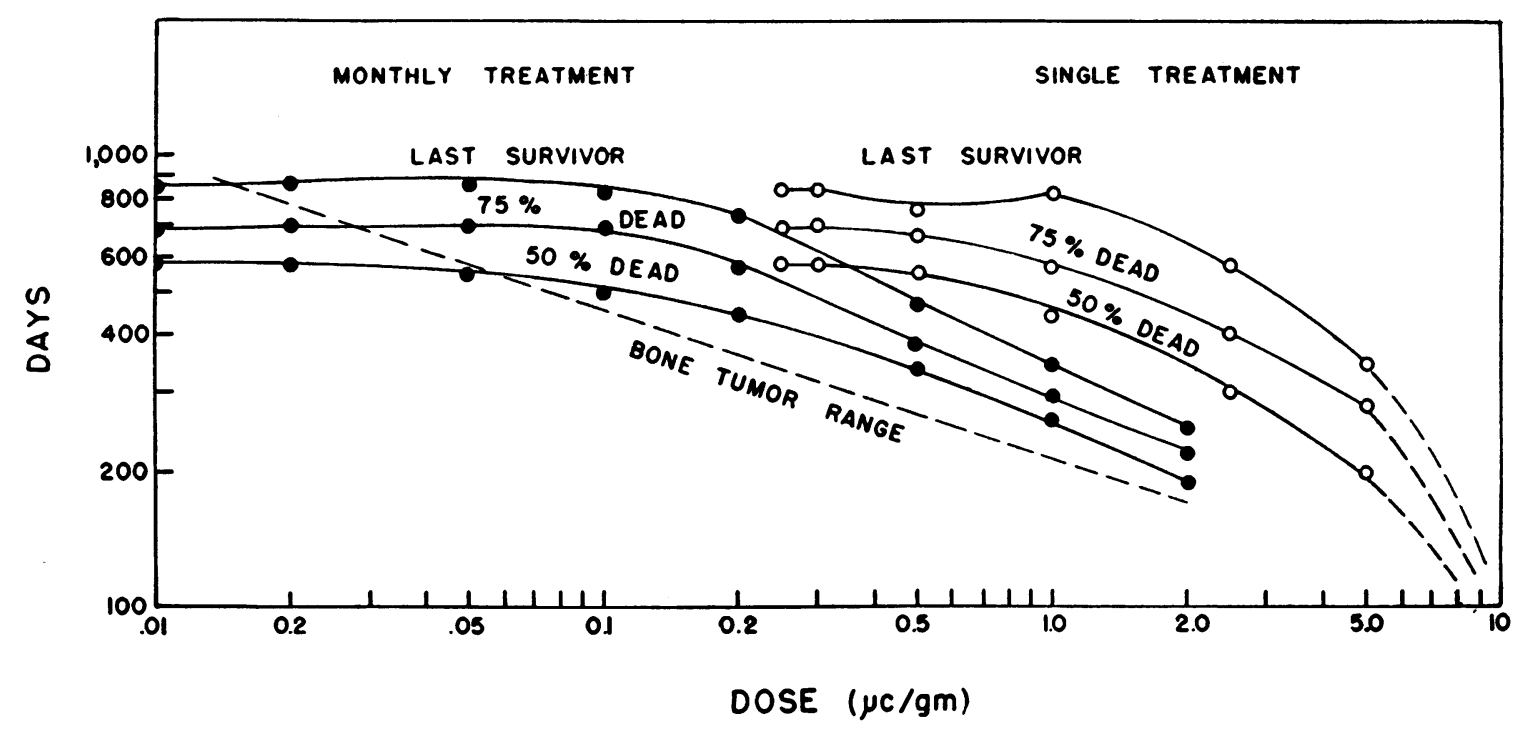

Fig. 1. Chart Showing Survival of Mice Given Various Doses of SR

Open circles represent single injections; closed circles, dose given monthly.

dosage increases. It may be postulated from this that one tumor, already present, does not suppress or stimulate the genesis of others.

A very striking feature of treatment with the higher dosages is the sharpness of the latent period, at the end of which tumors appear rapidly. It seems clear that the latent period cannot be explained (where a single dose is given) by the time required for a tumor to develop from a single cell if the cellular growth rate is constant, unless the tumor is formed some time after the greater part of the radiation has been delivered. As stated earlier, the prolonged latent period is characteristic of radiation carcinogenesis.

In attempting to understand quantitatively the process of carcinogenesis, the data have been plotted in a variety of ways. The simplest function was seen where the tumor morbidity rate was plotted directly against time, in mice given continuing dosage. These data are shown in Figure 2. The ordinates represent the probability that a mouse in a given dosage group will develop a tumor (or possess a tumor at a certain early stage of development) on a given day, and this figure is obtained by calculating, for 40-day overlapping time intervals, the proportion of mice which will die with bone tumors within 40 days. This figure, divided by 40 , gives the daily expectancy, or morbidity rate, $\mathrm{P}_{\mathrm{t}}$. The time scale is adjusted to the beginning of the 40 -day period before death, and therefore represents tumors at about the time they are first visible, or somewhat before that time.

It will be seen that this function gives essentially a straight line cutting the horizontal axis at the "latent time"; the slope of the line being proportional to dose, and the latent period varying gradually with dose, perhaps as a logarithmic function. The straight lines have been drawn in accordance with an empirical formula:

$$
P_{t}=K d\left(t-t_{e}\right)
$$

where $\left(t-t_{e}\right)$ represents time after the end of the latent period, and $\mathrm{d}$ is proportional to the dose, where the monthly dosage is expressed in $\mu \mathrm{c} / \mathrm{g}$, and time in days, and $\mathrm{K}$ is taken as $1.4 \times 10^{-4}$. The latent period may appear, on inspection, to vary with the logarithm of the dosage, or with an inverse root of the dosage (approximately the square root). The latter function is indicated, quite qualitatively, as a broken line in Figure 1, and shows graphically the impossibility of producing tumors with low dosages in short-lived animals.

It is significant that the accumulated number of tumors at any time after the end of the latent period is a function of $t \times P_{t}$, and hence of the square of time. In this way, it is seen that the low dosage required to induce radium tumors in man is consistent with the longer period in which tumors 


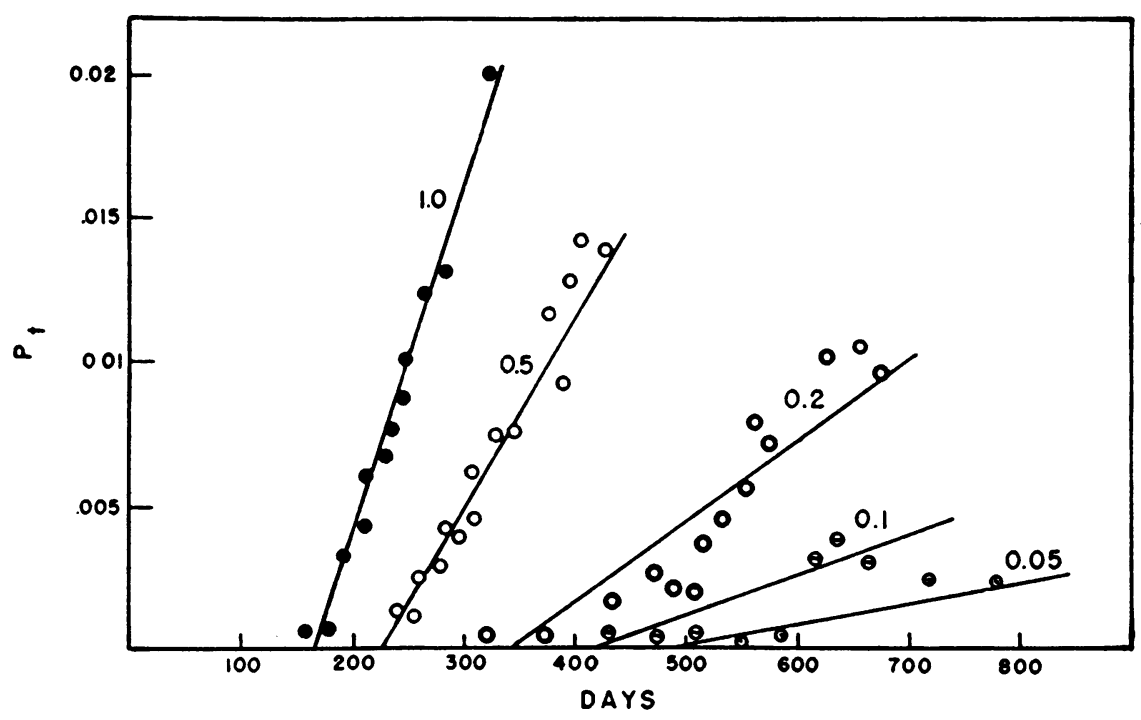

Fig. 2. Daily Probability of Bone Tumor Development ( $P_{t}$ ) as a Function of Time after Beginning of Monthly Injections

Figures beside the curves indicate dosages in $\mu \mathrm{c} / \mathrm{g}$.

may develop than in experimental animals. One semiquantitative expression of this has been stated (14). The data shown in Figure 2 may be interpreted in this way: that each quantity of absorbed radiation confers on the tissue absorbing it a probability of tumor formation which is without limit in time, once the latent period is passed; thus the daily tumor morbidity will constantly increase as long as further irradiation occurs.
I am indebted to Dr. R. D. Evans (31) for pointing out that the data shown here are also consistant with a Gaussian distribution of tumors around an optimal time after treatment, where the parameters are specified functions of dose. It would be virtually impossible to distinguish between these two expressions with such experimental data as can be obtained by the techniques used here.

When a single injection of $\mathrm{Sr}^{89}$ is given, we

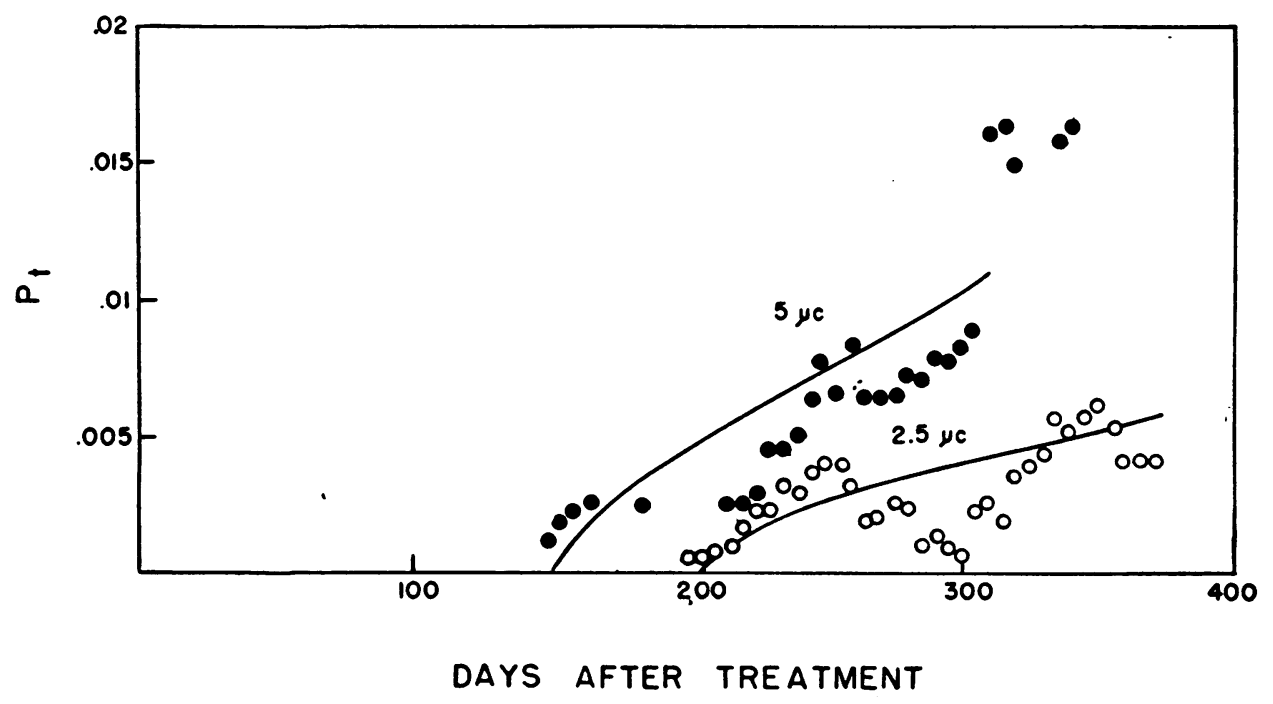

Fig. 3. Daily Probability of Tumor Development as a Function of Time after a Single Injection of $\mathrm{SR}^{*}$, AS In Figure 2 
might expect to see a somewhat simpler function. That this is not the case appears from Figure 3. Here we again see a sharply defined latent period, followed by an increase in tumor morbidity. These data also indicate that the subsequent morbidity is, within the limitations imposed by survival, relatively without limit in time after the latent period is passed.

Further data regarding the pattern of tumor formation in mice and in other species will be published in the future, when the pathologic data are complete. The preliminary results suggest that (1) in rats and mice, the tumor incidence following radium administration gives a ratio of effectiveness of radium: strontium ${ }^{89}$ of about $10: 1$ on a millicurie basis; and (2) that the response to boneseeking radioelements as regards latent period and tumor incidence per animal is comparable as between rats, mice, and rabbits, and is certainly no greater in dogs.

\section{DISCUSSION}

Such data as have been obtained from a variety of sources still fail to answer a number of questions which must be understood before it will be possible to make direct application of experimental data to man, especially in the tolerance range.

In the first place, the question whether there is a true threshold for carcinogenic effects appears to be entirely unanswered. The scantiness of human data on the one hand, and the short life-span of animals on the other, makes it impossible to say what effects might be seen in a large human population after a long period of time. The human experience has been reviewed by Evans (32) in some detail, and the author concludes that total dosages of 1000 to 10,000 rep for alpha radiation have been required to induce an incidence of 10 per cent tumors after 15 years. The X-ray data previously cited (11) and the bulk of animal data involving absorbed isotopes leave the impression that the lowest amount of X-radiation or beta radiation which has been clearly shown responsible for carcinogenesis (excepting mouse lymphoma) may be of the same order. It cannot be said whether underlying visible tissue changes are necessary to radiation carcinogenesis, or whether it is a statistical event that may (with a very low probability) occur whenever a cell lies in the path of ionization.

Secondly, the relation between life-span of a given species and the latent period before tumor formation requires study. In the matter of chemical carcinogenesis, it appears that the period of latency for the dog and man is longer than in the rodents. We are not aware that such a relationship has clearly been shown for radiation-induced neoplasia under controlled conditions.

Finally, the concept of the origin of malignant disease (whether a stray statistical event taking place in a single cell, or a systemic change) has considerable bearing on the relation between human and experimental results. The former concept is consistent with the observed distribution of tumors within a group of animals, since multiple primary bone tumors do not appear to occur with undue frequency. Assuming that cancer is a disease arising in a single cell, and that all the cells of a tissue are more or less equally susceptible to the change, it can be seen that even under a strong stimulus the carcinogenic event has a numerical rarity comparable to the incidence of genetic mutations. In that event, man might be expected by virtue of mass and cell number to have a susceptibility to tumor formation on the order of 1,000 times that of the mouse. It will be obvious that this is not the case, and that if it were, the survival of the larger species would be impossible. Thus the extrapolation of the carcinogenic effects of radiation from rodents to man involves unknown variables in several parameters, and poses some of the basic problems in cancer biology.

\section{SUM MARY}

The effects of large dosages of radioisotopes resemble to a marked extent those of total-body radiation, with modifications dependent on tissue distribution. Permissible exposure levels are determined by the late or chronic radiation changes, of which malignant changes have quite properly attracted major attention.

There is no evidence to indicate that radiation dosages to tissue corresponding to established "permissible" external dosages $(0.3-0.6 \mathrm{rep} /$ week) will result in an increased incidence of malignant disease detectable in a population of moderate size. In making such calculations, it is necessary to estimate maximum local tissue dosage, rather than the mean value for an organ or structure, and to make use of factors recognizing the greater effectiveness of ionization in areas 
where it is dense (e.g., alpha-particle ionization).

The suggestion is made that a more conservative figure is desirable where a large population may be affected, and the basis for using larger dosages in clinical investigation, diagnosis, and therapy is discussed.

Bone tumor induction by $\mathrm{Sr}^{89}$ has been studied extensively in mice. The data are consistent with the view that each given quantity of radiation to bone confers a given probability of bone tumor formation which may occur at any time following a "latent period." The latent period increases gradually with the dosage. It is not known at present whether a threshold exists for such effects.

\section{ACKNOWLEDGMENT}

The experimental work was done in collaboration with Drs. Hermann Lisco and Miriam Finkel, to whom the author is also indebted for valuable suggestions in the preparation of this paper.

\section{BIBLIOGRAPHY}

1. Zirkle, R. E., The radiobiological importance of specific ionization. Atomic Energy Commission Declassified Document No. MDDC 444, 1943.*

2. Parker, H. M., Advances in Biological and Medical Physics. Academic Press, Inc., New York, 1948, Vol. 1, p. 186.

3. Evans, R. D., Tissue dosage in radio-isotope therapy. Am. J. Roentgenol., 1947, 58, 754.

4. Brues, A. M., Effects of radiation on cell division. Tr. New York Acad. Sc., 1949, in press.

5. Marinelli, L. D., Dosage determination in the use of radioactive isotopes. J. Clin. Invest., 1949, 28, 1271.

6. Prosser, C. L., The clinical sequence of physiological effect of ionizing radiation in animals. Radiology, 1947, 49, 299.

7. Painter, E. E., and Brues, A. M., The radiation syndrome. New England J. Med., 1949, 240, 871.

8. Allen, J. G., Sanderson, M., Milham, M., Kirschon, A., and Jacobson, L. O., Heparinemia (?), an anticoagulant in the blood of dogs with hemorrhagic tendency after total body exposure to roentgen rays. J. Exper. Med., 1948, 87, 71.

9. Jacobson, L. O., Simmons, E. L., and Block, M. H., The effect of splenectomy on the toxicity of $\mathrm{Sr}^{\circ}$ to the hematopoietic system of mice. Atomic Energy Commission Declassified Document No. CH 3886, 1946.*

* Information concerning the availability of these documents may be obtained by addressing inquiries to the Document Distribution Section, Technical Information Division, Atomic Energy Commission, Oak Ridge, Tenn.
10. MacMahon, H. E., Murphy, A. S., and Bates, M. I., Endothelial-cell sarcoma of liver following thorotrast injections. Am. J. Path., 1947, 23, 585.

11. Cahan, W. G., Woodard, H. Q., Higinbotham, N. L., Stewart, F. W., and Coley, B. L., Sarcoma arising in irradiated bone. Cancer, 1948, 1, 3.

12. Henshaw, P. S., Riley, E. F., and Stapleton, G. E., The biologic effects of pile radiations. Radiology, 1947, 49, 349.

13. Grundhauser, W., cited by A. M. Brues, Lisco, H., and Finkel, M. P., in reference 14.

14. Brues, A. M., Lisco, H., and Finkel, M. P., Carcinogenic action of some substances which may be a problem in certain future industries. Abstract in Cancer Research, 1947, 7, 48. Atomic Energy Commission Declassified Document No. MDDC 145, 1946.*

15. Morgan, K. Z., Tolerance concentrations of radioactive substances. J. Physiol. \& Colloid Chem., 1947, 51, 984.

16. Marinelli, L. D., Quimby, E. H., and Hine, G. J., Dosage determination with radioactive isotopes. Nucleonics, 1948, 2, 56.

17. Finkle, R. D., Jacobson, L. O., Kisieleski, W., Lawrence, B., Simmons, E. L., and Snyder, R. H., The toxicity and metabolism of plutonium in laboratory animals. Atomic Energy Commission Declassified Document No. MDDC 1140, 1947.*

18. Threefoot, S., Burch, G., and Reaser, P., The biologic decay periods of sodium in normal man, in patients with congestive heart failure, and in patients with the nephrotic syndrome as determined by $\mathrm{Na}^{22}$ as the tracer. J. Lab. \& Clin. Med., 1949, 34, 1.

19. Peacock, W. C., Evans, R. D., Irvine, J. W., Jr., Good, W. M., Kip, A. F., Weiss, S., and Gibson, J. G., 2nd, The use of two radioactive isotopes of iron in tracer studies of erythrocytes. J. Clin. Invest., 1946, 25, 605.

20. Schulman, J., Jr., Falkenheim, M., and Gray, S. J., The phosphorus turnover of carcinoma of the human stomach as measured with radioactive phosphorus. J. Clin. Invest., 1949, 28, 66.

21. Keating, F. R., Jr., Power, M. H., Berkson, J., and Haines, S. F., The urinary excretion of radioiodine in various thyroid states. J. Clin. Invest., 1947, 6, 1138.

22. Libby, W. F., Anderson, E. D., and Arnold, J. R., Age determination by radiocarbon content: worldwide assay of natural radiocarbon. Science, 1949, 109, 227.

23. Hall, B. E., and Watkins, C. H., Radiophosphorus in treatment of blood dyscrasias. Med. Clin. North America, 1947, 31, 810.

24. Finkel, M. P., Brues, A. M., Sacher, G. A., and Lisco, H., Unpublished data presented at American Association for Cancer Research (1948).

25. Nickson, J. J., Dosimetric and protective considerations for radioactive iodine. J. Clin. Endocrinol., 1948, 8, 721. 
26. Haines, S. F., Keating, F. R., Jr., Power, M. H., Williams, M. M. D., and Kelsey, M. P., The use of radioiodine in the treatment of exophthalmic goiter. J. Clin. Endocrinol., 1948, 8, 813.

27. Evans, T. C., Lenz, M., Donlan, C., and LeMay, M., Effects of radioactive sodium on leukemia and allied disease. Am. J. Roentgenol., 1948, 59, 469.

28. Ducoff, H. S., Neal, W. B., Straube, R. L., Jacobson, L. O., and Brues, A. M., Biological studies with arsenic $^{\text {76 }}$. II. Excretion and tissue localization. Proc. Soc. Exper. Biol. \& Med., 1948, 69, 548.
29. Rawson, R. W., Marinelli, L. D., Skanse, B. N., Trunnell, J., and Fluharty, R. G., The effect of total thyroidectomy on the function of metastatic thyroid cancer. J. Clin. Endocrinol., 1948, 8, 826.

30. Prosser, C. L., France, H. O., Brues, A. M., and Henshaw, P. S., Unpublished data.

31. Evans, R. D., Personal communication (1948).

32. Evans, R. D., Quantitative aspects of radiation carcinogenesis in humans. Tr. of the Fourth International Cancer Research Congress, to be published. 